\title{
Association Between Objectively Measured Physical Activity And Musculoskeletal Disorders, And Perceived Work Ability Among Adult, Middle-Aged And Older Women
}

This article was published in the following Dove Press journal:

Clinical Interventions in Aging

\author{
Agnieszka Nawrocka (D) \\ Maria Niestrój-Jaworska (iD) ${ }^{2}$ \\ Arkadiusz Mynarski $\mathbb{D}^{2}$ \\ Jacek Polechoński' \\ 'Institute of Sport Science, The Jerzy \\ Kukuczka Academy of Physical Education, \\ Katowice, Poland; ${ }^{2}$ Department of \\ Physical Activity and Health Prevention, \\ The Jerzy Kukuczka Academy of Physical \\ Education in Katowice, Katowice, Poland
}

Correspondence: Agnieszka Nawrocka Institute of Sport Science, The Jerzy Kukuczka Academy of Physical Education, Mikolowska 72a, Katowice 40-065, Poland $\mathrm{Tel}+48322075169$

Email a.nawrocka@awf.katowice.pl
Purpose: The purpose of this study was to assess the relationship between objectively measured physical activity and perceived work ability and musculoskeletal disorders among adult, middle-aged, and older women.

Patients and methods: This study used a cross-sectional design with a convenience sample of 348 women divided into 3 age groups: 30-49 years $(n=111), 50-65$ years $(n=120), 66-75$ years $(n=117)$. Weekly physical activity was monitored using tri-axial accelerometer ActiGraph Gt3X. Perceived work ability was assessed using the standardized Work Ability Index (WAI) questionnaire. Information about the occurrence and intensity of musculoskeletal disorders was collected using standardized Nordic Musculoskeletal Questionnaire (NMQ) expanded by visual analog pain intensity scale (VAS).

Results: Regardless of age, women who met physical activity recommendations achieved higher scores in each part of the WAI, and also in the total WAI scores. However, the most significant differences were found in women aged 50-64 years, and included the following items: subjective work ability, work ability in relation to demands, work impairments, sick leave in the past year. Total WAI scores were also significantly higher in women aged 30-49 and 50-64 years who met PA recommendations in comparison to women who did not meet recommendations. Also, significant relations between the frequency of occurrence of musculoskeletal problems and meeting physical activity recommendations were found in women aged 50-64 years. Those who were more physically active reported less musculoskeletal problems in shoulders $(p=0.006)$ and ankles/feet $(p=0.018)$ regions.

Conclusion: Adherence to Global Recommendations on Physical Activity for Health disseminated by WHO is related to better-perceived work ability among adult (30-49 years) and middle-aged (50-64 years) women. There is also a relationship between adherence to recommendations of physical activity and frequency and intensity of musculoskeletal pain among middle-aged women.

Keywords: WHO recommendations, actigraph, WAI, NMQ, accelerometry, exercises

\section{Introduction}

Strong evidence has been gathered over the years about health benefits of regular physical activity. ${ }^{1-3}$ Physical exercise can be effective in primary and secondary prevention of chronic diseases (eg, heart disease, stroke, chronic respiratory diseases, cancer, and diabetes), ${ }^{4-6}$ which are the leading cause of premature death and disability. Numerous studies also confirmed that regular exercise reduces the risk of 
anxiety and depression, ${ }^{7-9}$ improves well-being ${ }^{10,11}$ and quality of life. ${ }^{12-14}$ Furthermore, physical activity is indicated as an independent predictor of successful aging. ${ }^{15-17}$ Physical activity in older people is critically important in the prevention of diseases, maintenance of functional capacity that guarantees one's independence. This has contributed to a systematic increase in the amount of research concerning health-related effects of various physical training interventions in middle-aged and older people. $^{18-21}$

Physical activity can prevent and reduce the occurrence of musculoskeletal disorders in populations of all ages. ${ }^{22-25}$ However, this is especially important in professionally active workers, as musculoskeletal pain can be the factor that reduces the ability and capacity to work. ${ }^{26,27}$ It should also be noted that the prevalence of musculoskeletal disorders (MSD)(including the joints, muscles, ligaments, nerves, tendons, and structures that support limbs, neck and back) increases with age. ${ }^{28}$ Therefore, special attention should be paid to the relation between physical activity and musculoskeletal symptoms among middle-aged and older adults who are still professionally active. Rapid aging in populations implies the need to implement a policy encouraging and supporting employment at an older age.

Some studies have shown the significant relationship between physical activity and the ability to work. ${ }^{29-31}$ Work ability can be defined as

having the health, competence and relevant occupational virtues required for managing some kind of job, assuming that the work tasks are reasonable and that the work environment is acceptable. ${ }^{32}$

Therefore, it should be noted that the concept of work ability is holistic and can be affected by various factors, such as, eg, work stressors, individual characteristics, and diseases. This raises the question of how work ability changes during work life and beyond. One of the factors related to better work ability is lifestyle, especially regular physical activity. To determine the minimal amount of health-related physical activity, the Global Recommendations on Physical Activity for Health were developed and disseminated by World Health Organization (WHO). According to these guidelines, adults and older adults should do at least 150 mins of moderate physical activity per week or at least 75 mins of vigorous physical activity per week.

The majority of studies that confirmed the relationship between health-related physical activity and work ability and musculoskeletal disorders were performed using the subjective method of physical activity assessment (questionnaires, self-assessment). The aim of this study was to assess the level of objectively measured physical activity according to health recommendations and to verify whether the perceived work ability and self-reported musculoskeletal disorders are associated with adherence to physical activity recommendations. We hypothesized that, regardless of age, women with a higher level of physical activity would achieve a better level of work ability and would report less musculoskeletal disorders.

\section{Materials And Methods Participants}

This study was approved by the Ethics Committee of The Jerzy Kukuczka Academy of Physical Education in Katowice. The study used a cross-sectional design with a convenience sample of volunteers from Katowice (Poland) who met the following inclusion criteria:

age (30-75 years), gender (female), work experience (at least 5 years), white-collar worker (declared mainly mentally demanding occupation or sedentary type of job for the majority of professional activity), consent to participate in the full research protocol (weekly monitoring of physical activity using accelerometer, completing WAI and NMQ questionnaires). Participants were recruited from purposely selected corporations in South Poland. The research project was promoted by posters and brochures. People interested in participation in the research were invited to meetings, where the aim of the study, protocol, and research tools were presented. The participants who did not meet the inclusion criteria, and those with missing data (incomplete measurement of physical activity based on adopted settings described in physical activity assessment section, incomplete questionnaires) were excluded from the analysis. Finally, 348 women were included in the analysis and divided into 3 age groups: 30-49 years $(n=111), 50-65$ years $(n=120), 66-75$ years $(n=117)$. The detailed participant characteristics are presented in Table 1.

This study was conducted in accordance with the Declaration of Helsinki and written informed consent was obtained from all participants.

\section{Physical Activity Assessment}

Physical activity was monitored using a 3-axial accelerometer ActiGraph Gt3X, worn on the right side of hip on the waistband. Women wore the physical activity monitor 
Table I Physical Features And Characteristics Of The Participants

\begin{tabular}{|c|c|c|}
\hline Variables & $\mathbf{n}$ & $\%$ \\
\hline \multicolumn{3}{|l|}{ Age } \\
\hline $30-49$ years & III & $31.9 \%$ \\
\hline $50-64$ years & 120 & $34.5 \%$ \\
\hline $65-75$ years & 117 & $33.6 \%$ \\
\hline \multicolumn{3}{|l|}{ BMI $\left[\mathrm{kg} / \mathrm{m}^{2}\right]$} \\
\hline 18-24.9 & 134 & $38.5 \%$ \\
\hline $25-30$ & 114 & $32.8 \%$ \\
\hline$>30$ & 100 & $28.7 \%$ \\
\hline \multicolumn{3}{|l|}{ Physical activity recommendations } \\
\hline Did not meet & 180 & $51.7 \%$ \\
\hline Met & 168 & $48.3 \%$ \\
\hline \multicolumn{3}{|l|}{ Work ability } \\
\hline Poor & 55 & $15.8 \%$ \\
\hline Moderate & 129 & $37.1 \%$ \\
\hline Good & 84 & $24.1 \%$ \\
\hline Excellent & 80 & $23.0 \%$ \\
\hline \multicolumn{3}{|l|}{ Musculoskeletal pain } \\
\hline No pain & 32 & $9.2 \%$ \\
\hline I-3 anatomical regions & 145 & $41.7 \%$ \\
\hline 4-6 anatomical regions & 127 & $36.5 \%$ \\
\hline$>6$ anatomical regions & 44 & $12.6 \%$ \\
\hline Total & 348 & $100.0 \%$ \\
\hline
\end{tabular}

for seven consecutive days of the week, with the exception of sleeping and water activities (eg, bathing, swimming). Data from physical activity monitors were collected according to the following settings: acceleration from three axes (vertical, mediolateral, anterior-posterior) combined into a vector magnitude score (VM), valid day defined as at least $10 \mathrm{hrs}$ of wear time, data integrated into 60 -second epochs and expressed as counts per minutes (cpm), non-wear time defined as 60 consecutive minutes of $0 \mathrm{cpm}$, with allowance for 1-2 mins of counts 0-200 cpm (Troiano algorithm modified for VM data), ${ }^{33,34}$ threshold counts values to identify the intensity of physical activity: 200-2689 cpm for light physical activity (LPA), 2690-6166 cpm for moderate physical activity (MPA), and more than $6167 \mathrm{cpm}$ for vigorous physical activity (VPA). ${ }^{35}$

Data collected from the Actigraph were analyzed with Actilife software to estimate the total time of performing moderate (MPA) and vigorous (VPA) physical activity during the monitored week. It allowed us to determe which of the studied women met the Global Recommendations on Physical Activity for Health popularized by the World Health Organization (WHO). ${ }^{36}$ According to these recommendations, participants were considered sufficiently physically active when they accumulated at least 150 mins of moderate physical activity (MPA) or at least 75 mins of vigorous physical activity (VPA) or an equivalent combination of moderate and vigorous physical activity (MVPA) during the week.

\section{Work Ability Assessment}

Perceived work ability was assessed using the standardized Work Ability Index (WAI) questionnaire. ${ }^{37,38}$ The index was derived as the sum of the ratings on the seven items, including current work ability compared with the lifetime best, work ability in relation to the demands of the job, number of current diseases diagnosed by physician, estimated work impairment due to diseases, sick leave during the past year (12 months), own prognosis of work ability two years from now, and mental resources.

The sum of scores was calculated ( 7 to 49 points), and also the four levels of the WAI were identified: poor (7-27 total scores), moderate (28-36 scores), good (37-43 scores), and excellent (44-49 scores). Therefore, this study included the results analyzed from each item, total WAI scores and the level of work ability.

\section{Musculoskeletal Disorders Assessment}

For assessment of musculoskeletal problems among participants, the standardized Nordic Musculoskeletal Questionnaire was used. ${ }^{39}$

This questionnaire includes a body map to indicate any musculoskeletal problems in nine anatomical regions (neck, shoulders, elbows, wrists/hands, upper back, lower back, hips/thighs, knees, and ankles/feet) over the past year and over the past week. In this study the NMQ questionnaire was expanded by adding a visual analog scale (VAS), which in case of problem complaints, also allowed to assess the pain intensity on a numerical scale 1-10 (1 - no pain; 10 -unbearable/worst pain).

\section{Statistical Analysis}

Descriptive statistics, such as statistical means (Mean) and standard deviations (SD) were used to describe the basic features of the quantitative data in the study, while qualitative variables were presented as percentages and frequencies. The non-parametric Kruskal-Wallis test (without multiple comparison tests) was used to compare quantitative variables between three age groups. Analysis of the level of work ability and musculoskeletal disorders among participants who met or did not meet physical activity recommendations 
was performed separately for each age group. The relations between physical activity level (defined as those who met or did not meet WHO physical activity recommendations) and quantitative variables (scores of work ability, total musculoskeletal symptoms and pain intensity) were assessed using Mann-Whitney $U$ test, and for the qualitative variables (percentage of participants with musculoskeletal problems in each anatomical region) using Chi-squared test. All analyses were performed using IBM SPSS 20 software. The level of significance of the $p$-value was set at 0.05 .

\section{Results}

The average amount of time spent on moderate physical activity (MPA) was insignificantly different in all studied groups (Table 2). The highest time of MPA was recognized in group aged 50-64 years (176 $\mathrm{min} /$ week), and the lowest in women aged 30-49 years (164 min/week). Opposite results were obtained in the case of vigorous physical activity (VPA). The average time of VPA significantly decreased with age and was respectively: $25.68 \mathrm{~min} /$ week in the youngest women, $13.07 \mathrm{~min} /$ week in women aged 50-64 years, and $9.5 \mathrm{~min} /$ week in women aged $65-75$ years $(p=0.008)$. It should also be noted that the number of women who performed vigorous intensity physical activity during the week was generally small and decreased with age.

Total work ability scores also significantly decreased with age $(p=0.000)$. Although there were no significant differences in the level of musculoskeletal disorders (MSD) declared in the last year, there were found in reported MSD and pain intensity during the last week. The women aged 30-49 years did not report any complaints at all, and the women aged $65-75$ years reported musculoskeletal disorders most frequently, and the pain intensity was the highest in comparison to the younger participants.

Due to some significant differences between women of various ages, further analyses were performed and presented separately for each age group. The next step of analysis was to verify the level and differences of work ability and musculoskeletal disorders among women sufficiently physically active (those who met the physical activity recommendations) and insufficiently physically active (those who did not meet physical activity recommendations) (Table 3). Regardless of age, women who met PA recommendations achieved higher scores in each part of the WAI, and also in the total WAI scores. However, the most significant differences were found in women aged 50-64 years, and included the following items: subjective work ability, work ability in relation to demands, work impairments, sick leave during past year. Total WAI scores were also significantly higher in women aged 30-49 and 50-64 years who met PA recommendations in comparison to women who did not meet recommendations.

Our results showed that musculoskeletal problems were common in all studied groups, regardless of the level of physical activity. The analysis did not show many significant relations between the frequency of occurrence of musculoskeletal problems in a particular anatomic region in the past year and adherence to physical activity recommendations (Table 4). The only significant relations were found in women aged 50-64 years. Those who were more physically active reported less musculoskeletal problems in shoulders $(p=0.006)$ and ankles/feet $(p=0.018)$ regions.

The next step of the analysis was to calculate the total amount of musculoskeletal disorders by adding up the occurrence of MSD from all anatomical regions reported

Table 2 Physical Activity Parameters, Work Ability Index, And Musculoskeletal Disorders Among Various Age Groups

\begin{tabular}{|c|c|c|c|c|c|c|c|c|c|c|}
\hline \multirow[t]{3}{*}{ Variables } & \multicolumn{9}{|l|}{ Age } & \multirow[t]{3}{*}{$p$-value } \\
\hline & \multicolumn{3}{|c|}{ 30-49 Years } & \multicolumn{3}{|c|}{ 50-64 Years } & \multicolumn{3}{|c|}{ 65-75 Years } & \\
\hline & $\mathbf{n}$ & Mean & SD & $\mathbf{n}$ & Mean & SD & $\mathbf{n}$ & Mean & SD & \\
\hline MPA (min/week) & III & 164.40 & 133.20 & 120 & 176.10 & 108.42 & 117 & 171.10 & 91.68 & 0.104 \\
\hline VPA (min/week) & 63 & 25.68 & 34.46 & 46 & 13.07 & 18.24 & 45 & 9.50 & 16.92 & 0.008 \\
\hline WAI score & 111 & 41.93 & 5.39 & 117 & 35.07 & 6.88 & 120 & 30.69 & 7.19 & $<0.001$ \\
\hline MSD (last year) & 111 & 3.21 & 2.03 & 117 & 3.83 & 2.31 & 120 & 3.80 & 2.64 & 0.112 \\
\hline MSD (last week) & - & - & - & 59 & 1.43 & 1.97 & 81 & 2.57 & 2.60 & $<0.001$ \\
\hline Pain intensity & - & - & - & 59 & 1.60 & 1.29 & 81 & 2.67 & 2.12 & 0.002 \\
\hline
\end{tabular}

Note: Bold values indicate statistical significance.

Abbreviations: MPA, moderate physical activity; VPA, vigorous physical activity; WAl, work ability index; MSD, musculoskeletal disorders (number of anatomical regions with declared pain); Kruskal-Wallis test. 
Table 3 Work Ability Among Women Who Met And Did Not Meet The Physical Activity (PA) Recommendations

\begin{tabular}{|c|c|c|c|c|c|c|c|}
\hline \multicolumn{3}{|c|}{ Variables } & \multicolumn{4}{|c|}{ Physical Activity Recommendations } & \multirow[t]{3}{*}{$p$-value } \\
\hline & & & \multicolumn{2}{|c|}{ Not Meet } & \multicolumn{2}{|l|}{ Meet } & \\
\hline & & & Mean & SD & Mean & SD & \\
\hline \multirow[t]{27}{*}{ Age } & \multirow[t]{9}{*}{$30-49$ years } & Subjective work ability & 7.76 & 1.62 & 8.19 & 1.61 & 0.162 \\
\hline & & Work ability in relation to demands & 4.03 & 0.77 & 4.28 & 0.73 & 0.063 \\
\hline & & Work ability in relation to demands & 4.34 & 0.68 & 4.37 & 0.62 & 0.906 \\
\hline & & Number of diseases & 5.72 & 1.54 & 6.33 & 1.06 & 0.033 \\
\hline & & Work impairments & 5.37 & 0.98 & 5.65 & 0.57 & 0.198 \\
\hline & & Sick leave in past year & 4.59 & 0.92 & 4.86 & 0.41 & 0.132 \\
\hline & & Prognosis of work ability & 5.84 & 1.64 & 6.16 & 1.51 & 0.245 \\
\hline & & Mental resources & 3.37 & 0.75 & 3.53 & 0.88 & 0.417 \\
\hline & & WAI score & 41.01 & 5.85 & 43.37 & 4.25 & 0.042 \\
\hline & \multirow[t]{9}{*}{$50-64$ years } & Subjective work ability & 6.35 & 1.99 & 7.55 & 1.85 & 0.002 \\
\hline & & Work ability in relation to demands & 3.64 & 0.97 & 4.00 & 0.76 & 0.047 \\
\hline & & Work ability in relation to demands & 3.91 & 0.87 & 4.13 & 0.85 & 0.141 \\
\hline & & Number of diseases & 4.78 & 1.75 & 5.21 & 1.71 & 0.092 \\
\hline & & Work impairments & 4.36 & 1.44 & 4.92 & 1.25 & 0.033 \\
\hline & & Sick leave in past year & 2.38 & 1.86 & 3.15 & 1.96 & 0.031 \\
\hline & & Prognosis of work ability & 4.55 & 1.92 & 4.90 & 1.39 & 0.382 \\
\hline & & Mental resources & 3.07 & 0.77 & 3.18 & 0.70 & 0.495 \\
\hline & & WAI score & 33.75 & 7.53 & 36.28 & 6.05 & 0.036 \\
\hline & \multirow[t]{9}{*}{$65-75$ years } & Subjective work ability & 6.19 & 2.12 & 6.74 & 1.90 & 0.127 \\
\hline & & Work ability in relation to demands & 3.39 & 0.83 & 3.82 & 0.77 & 0.003 \\
\hline & & Work ability in relation to demands & 3.63 & 0.88 & 3.86 & 0.73 & 0.107 \\
\hline & & Number of diseases & 4.84 & 1.33 & 4.96 & 1.60 & 0.187 \\
\hline & & Work impairments & 3.80 & 1.84 & 4.05 & 1.83 & 0.418 \\
\hline & & Sick leave in past year & 1.37 & 1.17 & 1.51 & 1.43 & 0.615 \\
\hline & & Prognosis of work ability & 4.00 & 1.75 & 4.12 & 1.72 & 0.752 \\
\hline & & Mental resources & 2.61 & 0.79 & 2.80 & 0.80 & 0.186 \\
\hline & & WAI score & 29.36 & 7.88 & 31.81 & 6.41 & 0.059 \\
\hline
\end{tabular}

Note: Bold values indicate statistical significance.

Abbreviations: WAl, work ability index; Mann Whitney U-test.

in the past year and last week (Table 5). Similar to our previous results, the only significant differences were found in women aged 50-65 years. Both the total MSD in the last year and the pain intensity in the last week were significantly higher in women who did not perform the recommended amount of physical activity.

\section{Discussion}

The main purpose of this study was to evaluate whether adherence to health-related physical activity recommendations is related to perceived work ability and musculoskeletal disorders among women of various ages. In this study, we only included women who declared mentally demanding occupations and sedentary type of job during the majority of their professional activity. This was because we monitored total weekly physical activity. Meanwhile, some studies have shown that occupational physical activity is not beneficial for health. ${ }^{40,41}$ Therefore, the majority of physical activity of our participants was performed during their leisure-time.

Our study did not show any significant differences between the level of moderate physical activity among various age groups. However, the intensity of weekly physical activity decreased with increasing age. These results support the data previously demonstrated by Ayabe et al. ${ }^{42}$

In our study, work ability level decreased with increasing age. Similar tendencies have been highlighted in previous studies. ${ }^{43,44}$ However, the number of reported musculoskeletal disorders in the last year did not differ 
Table 4 Percentages Of Musculoskeletal Disorders Among Women Who Met And Did Not Meet The Physical Activity (PA) Recommendations

\begin{tabular}{|c|c|c|c|c|c|c|c|c|c|c|}
\hline \multirow[t]{4}{*}{ Region } & \multirow{4}{*}{$\begin{array}{l}\text { Pain In The Last } \\
\text { Year }\end{array}$} & \multicolumn{9}{|l|}{ Age } \\
\hline & & \multicolumn{2}{|c|}{ 30-49 Years } & & \multicolumn{2}{|c|}{ 50-64 Years } & & \multicolumn{2}{|c|}{ 65-75 Years } & \\
\hline & & \multicolumn{2}{|c|}{$\begin{array}{l}\text { PA } \\
\text { Recommendations }\end{array}$} & \multirow[t]{2}{*}{$p$-value } & \multicolumn{2}{|c|}{$\begin{array}{l}\text { PA } \\
\text { Recommendations }\end{array}$} & \multirow[t]{2}{*}{$p$-value } & \multicolumn{2}{|c|}{$\begin{array}{l}\text { PA } \\
\text { Recommendations }\end{array}$} & \multirow[t]{2}{*}{$p$-value } \\
\hline & & $\begin{array}{l}\text { Did Not } \\
\text { Meet }\end{array}$ & Met & & $\begin{array}{l}\text { Did Not } \\
\text { Meet }\end{array}$ & Met & & $\begin{array}{l}\text { Did Not } \\
\text { Meet }\end{array}$ & Met & \\
\hline Neck & $\begin{array}{l}\text { No } \\
\text { Yes }\end{array}$ & $\begin{array}{l}29.9 \\
70.1\end{array}$ & $\begin{array}{l}36.6 \\
63.4\end{array}$ & 0.468 & $\begin{array}{l}29.6 \\
70.4\end{array}$ & $\begin{array}{l}42.4 \\
57.6\end{array}$ & 0.159 & $\begin{array}{l}38.9 \\
61.1\end{array}$ & $\begin{array}{l}49.2 \\
50.8\end{array}$ & 0.258 \\
\hline Shoulders & $\begin{array}{l}\text { No } \\
\text { Yes }\end{array}$ & $\begin{array}{l}64.2 \\
35.8\end{array}$ & $\begin{array}{l}65.9 \\
34.1\end{array}$ & 0.860 & $\begin{array}{l}35.2 \\
64.8\end{array}$ & $\begin{array}{l}61 \\
39\end{array}$ & 0.006 & $\begin{array}{l}57.4 \\
42.6\end{array}$ & $\begin{array}{l}52.3 \\
47.7\end{array}$ & 0.578 \\
\hline Upper back & $\begin{array}{l}\text { No } \\
\text { Yes }\end{array}$ & $\begin{array}{l}53.7 \\
46.3\end{array}$ & $\begin{array}{l}51.2 \\
48.8\end{array}$ & 0.800 & $\begin{array}{l}48.1 \\
51.9\end{array}$ & $\begin{array}{l}66.1 \\
33.9\end{array}$ & 0.054 & $\begin{array}{l}63 \\
37\end{array}$ & $\begin{array}{l}61.5 \\
38.5\end{array}$ & 0.873 \\
\hline Elbows & $\begin{array}{l}\text { No } \\
\text { Yes }\end{array}$ & $\begin{array}{l}91 \\
9\end{array}$ & $\begin{array}{l}82.9 \\
17.1\end{array}$ & 0.208 & $\begin{array}{l}77.8 \\
22.2\end{array}$ & $\begin{array}{l}88.1 \\
11.9\end{array}$ & 0.141 & $\begin{array}{l}83.3 \\
16.7\end{array}$ & $\begin{array}{l}86.2 \\
13.8\end{array}$ & 0.669 \\
\hline $\begin{array}{l}\text { Wrists/ } \\
\text { Hands }\end{array}$ & $\begin{array}{l}\text { No } \\
\text { Yes }\end{array}$ & $\begin{array}{l}78.8 \\
21.2\end{array}$ & $\begin{array}{l}78 \\
22\end{array}$ & 0.928 & $\begin{array}{l}59.3 \\
40.7\end{array}$ & $\begin{array}{l}67.8 \\
32.2\end{array}$ & 0.346 & $\begin{array}{l}59.3 \\
40.7\end{array}$ & $\begin{array}{l}53.8 \\
46.2\end{array}$ & 0.553 \\
\hline Lower back & $\begin{array}{l}\text { No } \\
\text { Yes }\end{array}$ & $\begin{array}{l}17.9 \\
82.1\end{array}$ & $\begin{array}{l}31.7 \\
68.3\end{array}$ & 0.099 & $\begin{array}{l}22.2 \\
77.8\end{array}$ & $\begin{array}{l}35.6 \\
64.4\end{array}$ & 0.118 & $\begin{array}{l}38.9 \\
61.1\end{array}$ & $\begin{array}{l}35.4 \\
64.6\end{array}$ & 0.707 \\
\hline $\begin{array}{l}\text { Hips/ } \\
\text { Thighs }\end{array}$ & $\begin{array}{l}\text { No } \\
\text { Yes }\end{array}$ & $\begin{array}{l}80.6 \\
19.4\end{array}$ & $\begin{array}{l}85.4 \\
14.6\end{array}$ & 0.528 & $\begin{array}{l}61.1 \\
38.9\end{array}$ & $\begin{array}{l}59.3 \\
40.7\end{array}$ & 0.846 & $\begin{array}{l}64.8 \\
35.2\end{array}$ & $\begin{array}{l}64.6 \\
35.4\end{array}$ & 0.982 \\
\hline Knees & $\begin{array}{l}\text { No } \\
\text { Yes }\end{array}$ & $\begin{array}{l}71.6 \\
28.4\end{array}$ & $\begin{array}{l}63.4 \\
36.6\end{array}$ & 0.372 & $\begin{array}{l}50 \\
50\end{array}$ & $\begin{array}{l}59.3 \\
40.7\end{array}$ & 0.320 & $\begin{array}{l}42.6 \\
57.4\end{array}$ & $\begin{array}{l}52.3 \\
47.7\end{array}$ & 0.291 \\
\hline $\begin{array}{l}\text { Ankles/ } \\
\text { Feet }\end{array}$ & $\begin{array}{l}\text { No } \\
\text { Yes }\end{array}$ & $\begin{array}{l}79.1 \\
20.9\end{array}$ & $\begin{array}{l}75.6 \\
24.4\end{array}$ & 0.672 & $\begin{array}{l}59.3 \\
40.7\end{array}$ & $\begin{array}{l}79.7 \\
20.3\end{array}$ & 0.018 & $\begin{array}{l}66.7 \\
33.3\end{array}$ & $\begin{array}{l}61.5 \\
38.5\end{array}$ & 0.562 \\
\hline
\end{tabular}

Note: Bold values indicate statistical significance.

Abbreviation: Chi-square test.

significantly between age groups. It could have been due to the fact that various musculoskeletal problems were very common in all tested women. Though, it should be noted that researchers and reports emphasize that the prevalence of musculoskeletal problems increases with aging. ${ }^{28,45}$ It could be caused by typical aging changes in musculoskeletal system, such as progressive loss of muscle mass and muscle strength (sarcopenia), and a decreased regenerative capacity. These changes are associated with impaired muscle metabolism, including mitochondrial dysfunction. However, a healthy lifestyle is a well-established countermeasure against muscle aging. ${ }^{46-48}$

Our results show that adherence to physical activity recommendations was related to better work ability among women, regardless of age. Similar results were observed among male workers. ${ }^{49}$ The beneficial relation between various parameters of physical activity and work ability has been recognized in many previous studies. ${ }^{30,31,50,51}$ Also, some studies have shown that physical exercise can reduce musculoskeletal problems and pain among both adults $^{25,52}$ and older people. ${ }^{24,53}$ In our study, similar results were observed in women aged 50-64 years. Both the prevalence of musculoskeletal problems reported in the past year, and intensity of musculoskeletal pain during last the week were significantly lower in women who met physical activity recommendations. These data confirm that physical activity has a positive influence on musculoskeletal aging. According to other studies, exercise has the potential to reverse and enhance the impaired mitochondrial function observed with aging. Exercise can attenuate age-related decreases in muscle mass, strength, 
Table 5 Musculoskeletal Disorders And Pain In All Anatomical Regions Among Women Who Met And Did Not Meet Physical Activity (PA) Recommendations

\begin{tabular}{|c|c|c|c|c|c|c|c|}
\hline \multicolumn{3}{|c|}{ Musculoskeletal Pain In All Anatomical Regions } & \multicolumn{4}{|c|}{ PA Recommendations } & \multirow[t]{3}{*}{$p$-value } \\
\hline & & & \multicolumn{2}{|c|}{ Did Not Meet } & \multicolumn{2}{|l|}{ Met } & \\
\hline & & & Mean & SD & Mean & SD & \\
\hline \multirow[t]{9}{*}{ Age } & $30-49$ years & Total MSD (last year) & 3.39 & 2.19 & 3.29 & 1.86 & 0.941 \\
\hline & & Total MSD (last week) & - & - & - & - & - \\
\hline & & Pain intensity (last week) & - & - & - & - & - \\
\hline & $50-64$ years & Total MSD (last year) & 4.57 & 2.43 & 3.41 & 1.89 & 0.009 \\
\hline & & Total MSD (last week) & 1.58 & 2.37 & 1.28 & 1.50 & 0.610 \\
\hline & & Pain intensity (last week) & 2.21 & 1.57 & 1.18 & 0.85 & 0.008 \\
\hline & $65-75$ years & Total MSD (last year) & 3.91 & 2.70 & 3.83 & 2.62 & 0.904 \\
\hline & & Total MSD (last week) & 2.53 & 2.53 & 2.62 & 2.68 & 0.953 \\
\hline & & Pain intensity (last week) & 2.61 & 1.68 & 2.72 & 2.45 & 0.579 \\
\hline
\end{tabular}

Note: Bold values indicate statistical significance.

Abbreviations: Total MSD, total musculoskeletal disorder (sum of the musculoskeletal disorders from all anatomic regions); Mann Whitney U-test.

and prevent impairments in muscle metabolism. ${ }^{46-48}$ Therefore, physical activity should be promoted as part of a healthy lifestyle essential to prevent musculoskeletal disorders during aging.

\section{Strengths And Limitations}

The main strength of this study is the objective measurement of weekly physical activity using the tri-axial accelerometer. This guarantees more accuracy of physical activity assessment in comparison to self-assessment using questionnaires. It has been confirmed in many studies that self-reported physical activity is often overestimated. ${ }^{54,55}$

Furthermore, including in the research, three various age groups give a better and more versatile view of the level and changes of assessed parameters during aging.

The main limitation of this study is the cross-sectional design with a convenience sample which does not allow assessment of the cause-effect relationship. In future studies, the evaluation of the influence of implemented physical activity programs on work ability and musculoskeletal disorders will be very valuable and needed. Another limitation is the fact that in the group aged 65-75 years, the majority of women were not professionally active. Therefore, the comparison of this group to the others does not reflect accurately the real state in the aspect of full-time employment. However, we included this age group to verify the potential of physical activity in increasing perceived ability to work, which is very important especially in the context of policy to encourage greater labor market participation at an older age.

\section{Conclusion}

Adherence to Global Recommendations on Physical Activity for Health disseminated by WHO is related to better perceived work ability among adults (30-49 years) and middle-aged (50-64 years) women. There is also a relationship between recommended physical activity and prevalence and intensity of musculoskeletal pain among middle-aged women.

\section{Study Implications}

Observed relationships between levels of physical activity in all studied groups and their ability to work suggest that the creation and implementation of health-enhancing physical activity programs (based on WHO recommendations) in order to maintain the ability to work and high quality of life in an aging population should be mandatory. Further studies of assessment of the relationship between physical activity and the ability to work and musculoskeletal disorders should be performed among employed older people, including specifically work-related musculoskeletal disorders.

\section{Disclosure}

The authors report no conflicts of interest in this work.

\section{References}

1. Warburton DER, Bredin SSD. Health benefits of physical activity: a systematic review of current systematic reviews. Curr Opin Cardiol. 2017;32(5):541-556. doi:10.1097/HCO.0000000000000437 
2. Reiner M, Niermann C, Jekauc D, Woll A. Long-term health benefits of physical activity-a systematic review of longitudinal studies. $B M C$ Public Health. 2013;13:813. doi:10.1186/1471-2458-13-813

3. Kokkinos P. Physical activity, health benefits, and mortality risk. ISRN Cardiol. 2012;2012:718789. doi:10.5402/2012/718789

4. Kyu HH, Bachman VF, Alexander LT, et al. Physical activity and risk of breast cancer, colon cancer, diabetes, ischemic heart disease, and ischemic stroke events: systematic review and dose-response metaanalysis for the Global Burden of Disease Study 2013. BMJ. 2016;354:i3857. doi:10.1136/bmj.i3857

5. Paudel S, Owen AJ, Owusu-Addo E, Smith BJ. Physical activity participation and the risk of chronic diseases among South Asian adults: protocol for a systematic review and meta-analysis. Syst Rev. 2018;7(1):177. doi:10.1186/s13643-018-0848-9

6. Kuijpers W, Groen WG, Aaronson NK, van Harten WH. A systematic review of web-based interventions for patient empowerment and physical activity in chronic diseases: relevance for cancer survivors. $J$ Med Internet Res. 2013;15(2):e37. doi:10.2196/jmir.2281

7. Belair MA, Kohen DE, Kingsbury M, Colman I. Relationship between leisure time physical activity, sedentary behaviour and symptoms of depression and anxiety: evidence from a populationbased sample of Canadian adolescents. BMJ Open. 2018;8(10): e021119. doi:10.1136/bmjopen-2017-021119

8. Yasunaga A, Shibata A, Ishii K, Koohsari MJ, Oka K. Cross-sectional associations of sedentary behaviour and physical activity on depression in Japanese older adults: an isotemporal substitution approach. $B M J$ Open. 2018;8(9):e022282. doi:10.1136/bmjopen-2018-022282

9. McDowell CP, Dishman RK, Hallgren M, MacDonncha C, Herring MP. Associations of physical activity and depression: results from the Irish Longitudinal Study on Ageing. Exp Gerontol. 2018;112:68-75. doi:10.1016/j.exger.2018.09.004

10. Abdin S, Welch RK, Byron-Daniel J, Meyrick J. The effectiveness of physical activity interventions in improving well-being across officebased workplace settings: a systematic review. Public Health. 2018;160:70-76. doi:10.1016/j.puhe.2018.03.029

11. Penedo FJ, Dahn JR. Exercise and well-being: a review of mental and physical health benefits associated with physical activity. Curr Opin Psychiatry. 2005;18(2):189-193.

12. Puciato D, Borysiuk Z, Rozpara M. Quality of life and physical activity in an older working-age population. Clin Interv Aging. 2017;12:1627-1634. doi:10.2147/CIA.S144045

13. Koolhaas CM, Dhana K, van Rooij FJA, Schoufour JD, Hofman A, Franco OH. Physical activity types and health-related quality of life among middle-aged and elderly adults: the Rotterdam Study. $J$ Nutr Health Aging. 2018;22(2):246-253. doi:10.1007/s12603-0170902-7

14. Van Dyck D, Teychenne M, McNaughton SA, De Bourdeaudhuij I, Salmon J. Relationship of the perceived social and physical environment with mental health-related quality of life in middle-aged and older adults: mediating effects of physical activity. PLoS One. 2015;10(3):e0120475. doi:10.1371/journal.pone.0120475

15. Gutierrez M, Tomas JM, Calatayud P. Contributions of psychosocial factors and physical activity to successful aging. Span J Psychol. 2018;21:E26. doi:10.1017/sjp.2018.27

16. Gopinath B, Kifley A, Flood VM, Mitchell P. Physical activity as a determinant of successful aging over ten years. Sci Rep. 2018;8 (1):10522. doi:10.1038/s41598-018-28526-3

17. Dogra S, Stathokostas L. Sedentary behavior and physical activity are independent predictors of successful aging in middle-aged and older adults. J Aging Res. 2012;2012:190654. doi:10.1155/2012/ 190654

18. Pilch W, Tota L, Sadowska-Krepa E, et al. The effect of a 12-week health training program on selected anthropometric and biochemical variables in middle-aged women. Biomed Res Int. 2017;2017:9569513. doi:10.1155/ 2017/9569513
19. Yoshiko A, Tomita A, Ando R, et al. Effects of 10-week walking and walking with home-based resistance training on muscle quality, muscle size, and physical functional tests in healthy older individuals. Eur Rev Aging and Phys Act. 2018;15:13. doi:10.1186/s11556-018-0201-2

20. Lai CC, Tu YK, Wang TG, Huang YT, Chien KL. Effects of resistance training, endurance training and whole-body vibration on lean body mass, muscle strength and physical performance in older people: a systematic review and network meta-analysis. Age Ageing. 2018;47(3):367-373. doi:10.1093/ageing/afy009

21. Garcia-Pinillos F, Laredo-Aguilera JA, Munoz-Jimenez M, LatorreRoman PA. Effects of 12-week concurrent high-intensity interval strength and endurance training programme on physical performance in healthy older people. J Strength Cond Res. 2017.

22. Nawrocka A, Mynarski W, Powerska A, Grabara M, Groffik D, Borek Z. Health-oriented physical activity in prevention of musculoskeletal disorders among young Polish musicians. Int J Occup Med Environ Health. 2014;27(1):28-37. doi:10.2478/s13382-014-0224-5

23. Morken T, Mageroy N, Moen BE. Physical activity is associated with a low prevalence of musculoskeletal disorders in the Royal Norwegian Navy: a cross sectional study. BMC Musculoskelet Disord. 2007;8:56. doi:10.1186/1471-2474-8-56

24. Murata S, Doi T, Sawa R, et al. Association between objectively measured physical activity and the number of chronic musculoskeletal pain sites in community-dwelling older adults. Pain Med. 2018;20:717-723.

25. Moreira-Silva I, Santos R, Abreu S, Mota J. The effect of a physical activity program on decreasing physical disability indicated by musculoskeletal pain and related symptoms among workers: a pilot study. Int $J$ Occup Saf Ergo. 2014;20(1):55-64. doi:10.1080/10803548.2014. 11077028

26. Bayattork M, Jakobsen MD, Sundstrup E, Seidi F, Bay H, Andersen LL. Musculoskeletal pain in multiple body sites and work ability in the general working population: cross-sectional study among 10,000 wage earners. Scand J Pain. 2018.

27. Zhang L, Huang C, Lan Y, et al. [Impact of work-related musculoskeletal disorders on work ability among workers]. Zhonghua Lao Dong Wei Sheng Zhi Ye Bing Za Zhi. 2015;33(4):245-249.

28. Briggs AM, Cross MJ, Hoy DG, et al. Musculoskeletal health conditions represent a global threat to healthy aging: a report for the 2015 World Health Organization World Report on Ageing and Health. Gerontologist. 2016;56 Suppl 2:S243-S255. doi:10.1093/geront/gnw002

29. Nawrocka A, Garbaciak W, Cholewa J, Mynarski W. The relationship between meeting of recommendations on physical activity for health and perceived work ability among white-collar workers. Eur J Sport Sci. 2018;18(3):415-422. doi:10.1080/17461391.2018.1424257

30. Wilke C, Ashton P, Elis T, Biallas B, Frobose I. Analysis of work ability and work-related physical activity of employees in a medium-sized business. BMC Res Notes. 2015;8:803. doi:10.1186/s13104-015-1781-9

31. Arvidson E, Borjesson M, Ahlborg G Jr., Lindegard A, Jonsdottir IH. The level of leisure time physical activity is associated with work ability-a cross sectional and prospective study of health care workers. BMC Public Health. 2013;13:855. doi:10.1186/1471-2458-13-855

32. Tengland PA. The concept of work ability. J Occup Rehabil. 2011;21 (2):275-285. doi:10.1007/s10926-010-9269-x

33. Aguilar-Farias N, Brown WJ, Peeters GM. ActiGraph GT3X+ cutpoints for identifying sedentary behaviour in older adults in freeliving environments. J Sci Med Sport. 2014;17(3):293-299. doi:10.1016/j.jsams.2013.07.002

34. Troiano RP, Berrigan D, Dodd KW, Masse LC, Tilert T, McDowell M. Physical activity in the United States measured by accelerometer. Med Sci Sports Exerc. 2008;40(1):181-188. doi:10.1249/ mss.0b013e31815a51b3

35. Sasaki JE, John D, Freedson PS. Validation and comparison of ActiGraph activity monitors. J Sci Med Sport. 2011;14(5):411-416. doi:10.1016/j.jsams.2011.04.003 
36. World Health Organization. Global Recommendations on Physical Activity for Health. World Health Organization; 2010.

37. Tuomi K, Ilmarinen J, Jahkola A, Katajarinne L, Tulkki A. Work Ability Index. Institute of Occupational Health Helsinki; 1994.

38. Ilmarinen J. The work ability index (WAI). Occup Med. 2007;57 (2):160. doi:10.1093/occmed/kqm008

39. Kuorinka I, Jonsson B, Kilbom A, et al. Standardised Nordic questionnaires for the analysis of musculoskeletal symptoms. Appl Ergon. 1987;18(3):233-237. doi:10.1016/0003-6870(87)90010-х

40. Holtermann A, Krause N, van der Beek AJ, Straker L. The physical activity paradox: six reasons why occupational physical activity (OPA) does not confer the cardiovascular health benefits that leisure time physical activity does. Br J Sports Med. 2018;52(3):149-150. doi:10.1136/bjsports-2017-097965

41. Hallman DM, Birk Jorgensen M, Holtermann A. On the health paradox of occupational and leisure-time physical activity using objective measurements: effects on autonomic imbalance. PLoS One. 2017;12(5):e0177042. doi:10.1371/journal.pone.0177042

42. Ayabe M, Yahiro T, Yoshioka M, Higuchi H, Higaki Y, Tanaka H. Objectively measured age-related changes in the intensity distribution of daily physical activity in adults. $J$ Phys Act Health. 2009;6(4):419425. doi:10.1123/jpah.6.4.419

43. Monteiro MS, Ilmarinen J, Corraa Filho HR. Work ability of workers in different age groups in a public health institution in Brazil. Int J Occup Saf Ergo. 2006;12(4):417-427. doi:10.1080/10803548.2006.11076703

44. Converso D, Sottimano I, Guidetti G, Loera B, Cortini M, Viotti S. Aging and work ability: the moderating role of job and personal resources. Front Psychol. 2017;8:2262. doi:10.3389/fpsyg.2017.02262

45. Holmstrom E, Engholm G. Musculoskeletal disorders in relation to age and occupation in Swedish construction workers. Am J Ind Med. 2003;44(4):377-384. doi:10.1002/ajim.10281

46. Peterson CM, Johannsen DL, Ravussin E. Skeletal muscle mitochondria and aging: a review. $J$ Aging Res. 2012;2012:194821. doi:10.1155/2012/194821
47. Hood DA, Memme JM, Oliveira AN, Triolo M. Maintenance of skeletal muscle mitochondria in health, exercise, and aging. Annu Rev Physiol. 2019;81:19-41. doi:10.1146/annurev-physiol-020518-114310

48. Distefano G, Goodpaster BH. Effects of exercise and aging on skeletal muscle. Cold Spring Harb Perspect Med. 2018;8(3): a029785. doi:10.1101/cshperspect.a029785

49. Paivarinne V, Kautiainen H, Heinonen A, Kiviranta I. Relationships of leisure-time physical activity and work ability between different occupational physical demands in adult working men. Int Arch Occup Environ Health. 2019;92:739-746.

50. Calatayud J, Jakobsen MD, Sundstrup E, Casana J, Andersen LL. Dose-response association between leisure time physical activity and work ability: cross-sectional study among 3000 workers. Scand $J$ Public Health. 2015;43(8):819-824. doi:10.1177/1403494815600312

51. Madeleine P, Vangsgaard S, Hviid Andersen J, Ge HY, Arendt-Nielsen L. Computer work and self-reported variables on anthropometrics, computer usage, work ability, productivity, pain, and physical activity. $B M C$ Musculoskelet Disord. 2013;14:226. doi:10.1186/1471-2474-14-226

52. Pereira CC, Lopez RF, Vilarta R. Effects of physical activity programmes in the workplace (PAPW) on the perception and intensity of musculoskeletal pain experienced by garment workers. Work. 2013;44(4):415-421. doi:10.3233/WOR-131517

53. Pan F, Byrne KS, Ramakrishnan R, Ferreira M, Dwyer T, Jones G. Association between musculoskeletal pain at multiple sites and objectively measured physical activity and work capacity: results from UK Biobank study. J Sci Med Sport. 2018.

54. Hagstromer M, Ainsworth BE, Oja P, Sjostrom M. Comparison of a subjective and an objective measure of physical activity in a population sample. J Phys Act Health. 2010;7(4):541-550. doi:10.1123/jpah.7.4.541

55. Wick K, Faude O, Schwager S, Zahner L, Donath L. Deviation between self-reported and measured occupational physical activity levels in office employees: effects of age and body composition. Int Arch Occup Environ Health. 2016;89(4):575-582. doi:10.1007/ s00420-015-1095-1
Clinical Interventions in Aging

\section{Publish your work in this journal}

Clinical Interventions in Aging is an international, peer-reviewed journal focusing on evidence-based reports on the value or lack thereof of treatments intended to prevent or delay the onset of maladaptive correlates of aging in human beings. This journal is indexed on PubMed Central, MedLine, CAS, Scopus and the Elsevier

\section{Dovepress}

Bibliographic databases. The manuscript management system is completely online and includes a very quick and fair peer-review system, which is all easy to use. Visit http://www.dovepress.com/ testimonials.php to read real quotes from published authors. 